\title{
ICEBERG UTILIZATION
}

[A review by Gordon Robin* of Iceberg utilization: Proceedings of the first international conference. Ames, Iowa, edited by A. A. Husseiny. Oxford, Pergamon, 1978, 760 p. Hardcover US\$60, soft cover \$30.]

Recent publicity has been given to the vast amount of fresh water floating on the ocean in the form of icebergs. If this frozen fresh water could be towed to arid regions and the water recovered, desert areas could be opened up to agriculture to the general benefit of man. Despite the enormous scientific and engineering problems involved, the potential value of iceberg harvesting is so great that, even if the chances of developing such an industry were only one in ten or even less, a strong case can be made for investigating these problems. This could in turn lead to pilot projects in locations where success is most likely.

The first international conference on iceberg utilization, held at the Iowa State University from 2-6 October 1977, brought together some 200 engineers, glaciologists, hydrologists, lawyers and industrialists to discuss the practicability of using icebergs, mainly for provision of fresh water. Another application of importance is their potential contribution to power generation. The conference was initiated primarily by engineers and scientists from Saudi Arabia under the leadership of Prince Mohammed Al-Faisal with support from the National Science Foundation, Iowa State University and others. The proceedings of the conference present a varied collection of papers that bring out many surprising and interesting aspects of the proposals.

The opening section, 'Overview', starts with comments by H. Guyford Stever, former Science Consultant to the US President and a former Director of the National Science Foundation. As well as emphasizing the need for fresh water in many nations, he points out that risk taking is somewhat in neglect these days. He concludes by quoting William Blake: 'He who would do good to another must do it in minute particulars. General good is the plea of the scoundrel, the hyprocrite and the flatterer, for art and science cannot exist but in minutely organized particulars'. It is the papers dealing in particulars that provide the greatest interest in the volume.

Several contributors agree with earlier findings of W. F. Weeks and W. J. Campbell (1973) ${ }^{1}$ and J. L. Hult and N. C. Ostrander $(1974)^{2}$, that towing of tabular icebergs from Antarctica to Southern Hemisphere continents at a speed of the order of one knot would result in more than half of the ice mass reaching its destination without melting. There seems to be general agreement that it is not possible to tow icebergs to places such as Saudi Arabia unless effective methods are found of insulating the bergs, primarily against melting by warm ocean waters, a process which causes much greater loss than melting by solar energy and atmospheric warmth.

It appears that the use of the largest conventional tugs for towing will bring a berg of the order of $1000 \mathrm{~m}$ by $500 \mathrm{~m}$ in area to a Southern Hemisphere destination such as Freemantle at a cost of a few per cent of the landed value of the water contained therein. A start was made in discussing the problems of handling the ice at its destination. Techniques include fairly conventional methods of mining ice from the berg before shipping it the last few kilometres to shore, the use of ice/water slurries for pipeline transport to shore, and cutting up the iceberg into manageable blocks, presumably for towing ashore.

As well as conventional towing, several other transport techniques of varying complexity and feasibility are proposed. The one that appeals most to this reviewer is the use of huge parachutes as sea anchors to winch the iceberg along. In principle, if one had a huge wire running along the sea bed from Antarctica to Australia, one could winch the berg the whole way. At a more practical and economic level, however, a huge drogue could provide the sea anchor on which to pull a rope of some $20 \mathrm{~km}$ length. Once the drogue is winched in this distance, it is laid out again by a tug for the next tow. This system is claimed to be six times more efficient in terms of tug horsepower than a conventional tug.

Even more daunting than towing problems are those of insulation of an iceberg against melting for transport through warmer waters. A vast industrial effort from the foamed plastic industry appears necessary, although one does not like to contemplate the many acres of plastic foam that could be torn off in a storm to provide yet more flotsam to be washed ashore on distant beaches.

1 Icebergs as a fresh water source: an appraisal, fournal of Glaciology, Vol 12, No 65, p 207.

2 Antarctic icebergs as a global fresh water resource. Santa Monica, California, Rand Corporation. (Rand Report R-1255-NSF.) 
The use of icebergs as a heat sink for power generation is an aspect that appears to have considerable economic potential if the latent heat involved in melting the ice could be used for this purpose. The 80 calories per gramme of latent heat of ice may be only one per cent of the energy of combustion of fossil fuel, but the cost of bringing ice to a power station may be less than one per cent of the price of the fossil fuel, so its relevance to thermodynamic efficiency may be significant. In any case, the ice must be melted before it can be used for agriculture.

The breadth of the symposium is shown by papers dealing with international law and iceberg utilization, comparisons with other methods of water transport and with water production by desalination, effects of large icebergs on local weather and one paper on the general ecological effects of icebergs.

Clearly we still have far to go in learning if large scale handling of icebergs is feasible. The technical difficulties and risks to human and animal life involved in towing potentially unstable but vast slabs of floating ice are formidable. It is not known whether the ecological effects of cold ice in warm water would damage or enhance the fishing industry, nor whether inhabitants of warm countries would really welcome the cold air coming off an iceberg during their cooler months. There is indeed ample scope for critics to show why the project will not work, and like the bolder exploratory projects of the past few decades, such as space exploration, deep-sea exploration, and the exploration of Antarctica, returns on the efforts invested may take so long to come that only the rich nations can afford the risks involved.

In the belief that the idea of using icebergs to benefit man is worth pursuing, an invitation has gone out from the Scott Polar Research Institute to hold the second international conference on the use of icebergs in Cambridge from 31 March to 3 April 1980. Organization of the meeting, which is now well underway, is in the hands of the International Glaciological Society, under the general direction of committees representing interested and supporting organizations, among whom Prince Faisal and his colleagues from Saudi Arabia are again giving much help. The meeting will concentrate on the scientific and practical feasibility of the use of icebergs. We look forward to a hard headed, critical, but one hopes stimulating meeting.

\section{$\mathbb{I N} \mathbb{B R I \mathbb { E }}$}

\section{SWEDISH ARCTIC EXPEDITION 1980}

One hundred years after the Swedish ship Vega fought her way through the North-east Passage, the Royal Swedish Academy of Sciences is organizing an Arctic research programme to take place during 1980. The original idea was to conduct the expedition along the same route as that covered by the Vega in 1878-79. It is now planned, however, to focus activities on the Barents Sea, the waters around Svalbard and the Greenland Sea. Atmospheric studies, marine biology and an earth science programme will be the three priority areas of research.

The Swedish government will make available one of their new state icebreakers, probably Ymer, and two helicopters will be carried for ice navigation and research purposes. In addition to a crew of 50 there will be space available for about 40 scientists and technicians. The expedition welcomes participation by scientists from all countries with important research projects which could be included in one of the three priority programmes. Further information may be obtained by writing to: YMER-80, Department of Physical Geography, Box 6801, S-113 86 Stockholm, Sweden. 